\title{
Linking disaster risk reduction, climate change, and the sustainable development goals
}

By Ilan Kelman, University College London (UK) and University of Agder (Norway)

\section{International agreements}

Several major international agreements related to sustainable development were signed in 2015 including:

- The Paris Agreement (UNFCCC, 2015) from the Conference of Parties 21 meeting (COP21) of the United Nations Framework Convention on Climate Change (UNFCCC) which was signed in December;

- The Sustainable Development Goals (SDGs; UNGA, 2015) which were approved in September;

- The Sendai Framework for Disaster Risk Reduction (SFDRR; UNISDR, 2015) which was signed in March.

Each of these three agreements differs in structure, legal context, and implementation mechanisms, but they also have numerous parallels.

One of the biggest differences is that the UNFCCC process which frames the COP meetings and agreements is meant to be legally binding in international law, whereas the processes leading to, and the outcomes from, the SDGs and SFDRR are voluntary. Yet the main provisions of the Paris Agreement are effectively voluntary, despite being enshrined in a legally binding process. Other major similarities are that all three agreements are based in the timeframe 2015-2030 and articulate the same fundamental ethos of sustaining human life without harming the planet or humanity. Meanwhile, processes similar to and in parallel with UNFCCC exist for biodiversity through the Convention on Biological Diversity (CBD) and the UN Convention to Combat Desertification (CCD).

Given the multiple agreements alongside their connections and overlaps, could they interfere with or support each other? Could further links be forged or should the processes be made entirely separate? One major challenge for the Paris Agreement is retaining relevance within the wider contexts of the SDGs, SFDRR, and the topics which those agreements cover. This overall challenge is detailed in the next two sections which explore how the Paris Agreement relates to disaster risk reduction and sustainable development. This paper's final section provides a resolution for the challenge through placing climate change within wider disaster risk reduction and sustainable development contexts.

\section{The Paris Agreement and disaster risk reduction through SFDRR}

Kelman (2015) analyses the 15 mentions of climate change in SFDRR yielding three main conclusions. First, climate change's influence on disasters and disaster risk is overplayed because vulnerability is the main cause of disasters and disaster risk yet climate change affects mainly hazards. Second, SFDRR appropriately offers disaster risk reduction ideas and expertise to climate change and SDG activities, but supports the artificial separation of climate change, disaster risk reduction, and sustainable development. Third, climate change as one hazard influencer amongst many receives too much attention compared to other hazard influencers. Overall, climate change's impact on SFDRR has been mainly to regress to a hazard-centric viewpoint thereby downplaying the political root causes of disaster vulnerability, even while SFDRR appropriately highlights vulnerability and root causes, as per the definition of disaster risk reduction. 
The Paris Agreement includes a single reference to SFDRR in the preamble through "Welcoming the adoption" of SFDRR and other international agreements. No other reference to disasters or disaster risk reduction appears in the Paris Agreement. Aspects of risk(s) from climate change are mentioned in only Article 8 of the Paris Agreement, along with some mentions in the text preceding the agreement. The Paris Agreement effectively ignores disaster risk reduction and this field's richness, divorcing itself entirely from SFDRR.

Yet the Paris Agreement accepts in principle the importance of disaster risk reduction processes, despite not connecting climate change to this wider context. Article 7, paragraph 1 of the Paris Agreement states "Parties hereby establish the global goal on adaptation of enhancing adaptive capacity, strengthening resilience and reducing vulnerability to climate change". This vocabulary relates to aspects of disaster risk reduction, but the clause exposes a fundamental flaw in the framing of climate change.

By focusing on only "reducing vulnerability to climate change", the Paris Agreement makes itself relevant to climate change only. This focus is not entirely inappropriate, since the Paris Agreement is about only climate change, is facilitated by the UN's climate change institution (UNFCCC), and is endorsed by national governments seeking to tackle climate change. Difficulties emerge when the focus on reducing vulnerability to climate change creates or exacerbates other disaster risk problems.

For example, due to climate change, tropical cyclone intensity is expected to increase, but frequency is expected to decrease, (Knutson et al., 2010). A useful engineering technique for reducing building vulnerability to intense tropical cyclones is providing heavy roofs strongly tied to the walls. Heavier roofs tend to increase earthquake casualties if they collapse. This concern is not merely theoretical. On 17 January 1995, many of the casualties in Kobe, Japan's earthquake were caused by the collapse of roofs deliberately designed to be heavy due to building codes written with typhoons presumed to be the principal damaging natural hazard (Menoni, 2001). Implementing the Paris Agreement by reducing building vulnerability to increasingly intense typhoons without considering other hazards could exacerbate earthquake casualties in locations experiencing both hazards.

\section{The Paris Agreement and sustainable development through the SDGs}

SDG Goal 13 is "Take urgent action to combat climate change and its impacts*" with the asterisk referring to a note reading "* Acknowledging that the United Nations Framework Convention on Climate Change is the primary international, intergovernmental forum for negotiating the global response to climate change". Although the text of UNGA (2015) mentions climate change frequently prior to listing the SDGs, just two other targets mention climate change explicitly:

- 2.4 in relation to "sustainable food production systems" and "resilient agricultural practices".

-11.b in terms of "the number of cities and human settlements" adequately addressing climate change.

Consequently, climate change is poorly integrated into the SDGs, instead being deliberately and explicitly separated from them. Even Goal 7 "Ensure access to affordable, reliable, sustainable and modern energy for all" does not mention climate change, despite being directly connected to climate change mitigation.

The Paris Agreement makes only passing reference to the SDGs, in the preamble in terms of "Welcoming the adoption" of UNGA (2015) "in particular its goal 13" which is the climate change goal. No other mention of the SDGs or UNGA (2015) appears in the Paris Agreement. It 
fully acknowledges sustainable development and in many paragraphs frames climate change "in the context of sustainable development" (e.g. Article 2, paragraph 1) or aims to "promote sustainable development" (e.g. Article 6, paragraphs 1 and 2), but with no direct connection to the SDGs.

Framing climate change within sustainable development is a positive aspect of the Paris Agreement, including numerous paragraphs which directly connect to several other linked processes including "efforts to eradicate poverty" (e.g. Article 2, paragraph 1) and promoting "environmental integrity" (e.g. Article 6, paragraph 1). These processes are already delineated with principles and targets in the SDGs, yet the Paris Agreement does not reference them. Much stronger and much more practical bridges could have been made by drawing on the SDGs for backstopping the Paris Agreement.

Although parts of the Paris Agreement were structured and written prior to the SDGs being adopted in September 2015, the final SDGs do not differ extensively in principle or structure from drafts available months earlier. UNFCCC held key COP21 negotiations in October 2015, after the SDGs had been adopted, and the Paris Agreement was not finalised until December 2015 with numerous changes in the text occurring during COP21. Ample opportunity existed to place the Paris Agreement within the SDGs in order to operationalise sustainable development's meaning and to better connect with the SDGs. This opportunity was not grasped, enhancing climate change's position as being separate from other processes.

\section{Resolution: Place climate change within wider contexts}

Climate change mitigation entails pollution prevention activities which have long been enacted for many other human emissions. Examples are persistent organic pollutants (e.g. PCBs and dioxins) and acid rain forming compounds (e.g. sulphur dioxide and nitrogen oxides). Each substance, including each greenhouse gas, requires its own social and technical approaches for reducing emissions or increasing uptake. The principles and categories are the same for all, such as physical, chemical or biological capture; product or process substitution; and people reducing their consumption of products and services. Climate change mitigation is pollution prevention which itself has long sat within sustainable development endeavours.

Climate change adaptation embraces a suite of activities aimed at reducing risks and exploiting benefits from extremes or changes in the climate. These activities are explicitly encompassed within disaster risk reduction's definition.

Flood, weather, and drought risk reduction enacted for climate change adaptation is exactly the same as being enacted for wider disaster risk reduction (e.g. Wisner et al., 2004). Efforts to change crops and to extend growing seasons based on the changing climate fall directly within previous efforts to use local knowledge for enhancing food security specifically for disaster risk reduction (e.g. Fleuret, 1986).

Consequently, climate change provides little which is new in the context of sustainable development. Meanwhile, climate change's two actions, adaptation and mitigation, continue to be separated even though they have much in common. Climate change could usefully be placed within other sustainable development activities to avoid separating it from other activities and to accept all the overlaps and links, as shown in Figure 1. 


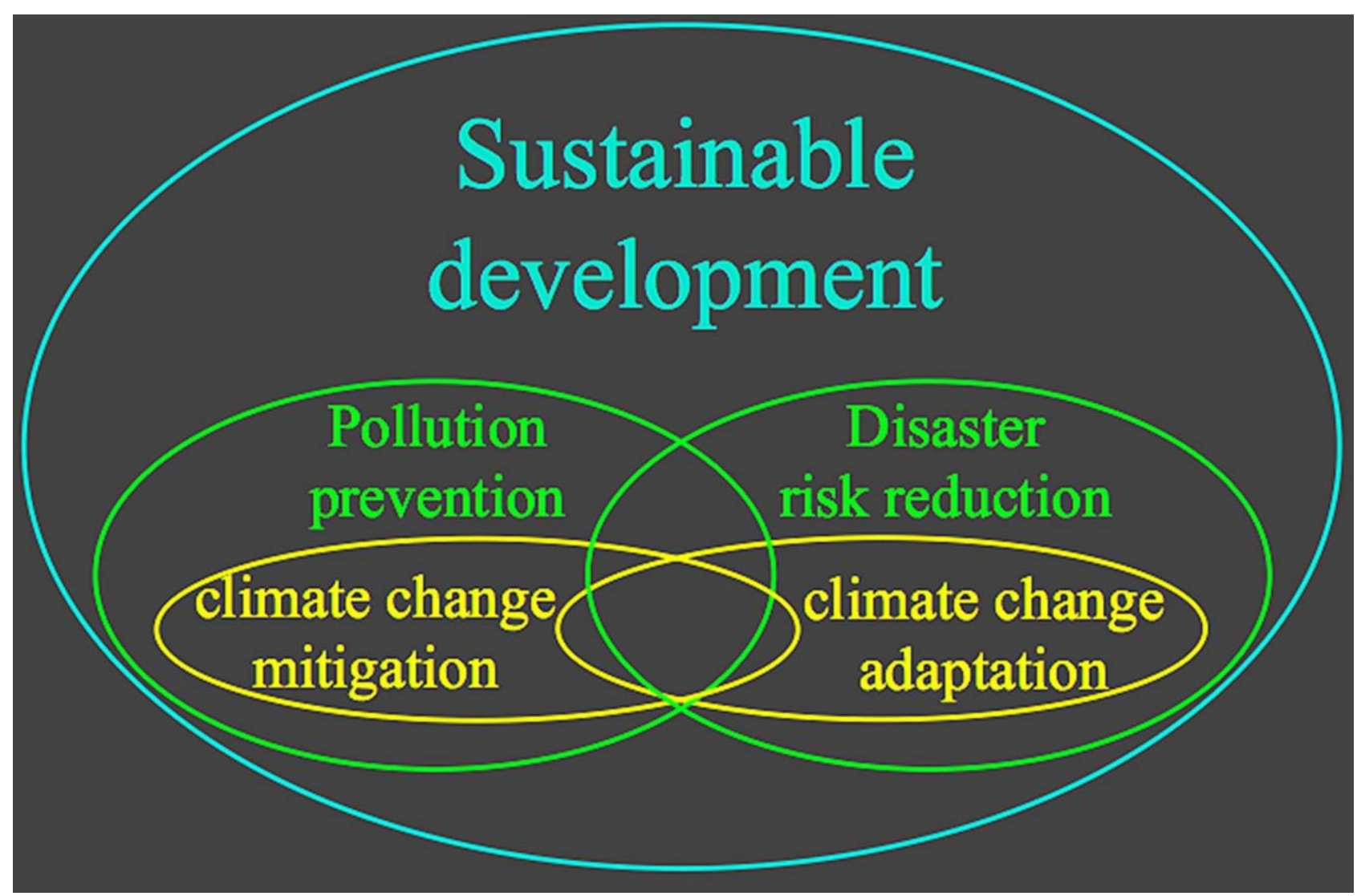

Figure 1: Connecting climate change, disaster risk reduction, and sustainable development

Consequently, the Paris Agreement provides little which could not be covered within other contexts. Yet those contexts, such as the SDGs and SFDRR, deliberately isolate climate change and do not take responsibility for addressing it. They cannot take responsibility for climate change because climate change has been sequestered for UNFCCC, deliberately isolating it. This approach creates and perpetuates separation amongst sustainable development topics and the international processes designed to deal with them.

The reason is principally due to the inertia of existing organisations and mechanisms, with the international institutions unwilling to cede power and territory while recognising the artificial political realities of encroaching on each other's approaches. These artificial politics are inhibiting the most effective action on multiple sustainable development processes simultaneously, indicating how the best sustainable development science does not necessarily affect what occurs operationally at the international level.

The key points from analysing the Paris Agreement within wider sustainable development contexts are:

- Climate change mitigation is no different from pollution prevention, so it sits within that topic which sits within sustainable development.

- Climate change adaptation is no different from disaster risk reduction, so it sits within that topic which sits within sustainable development.

- Climate change and its agreements should be enfolded within, not separated from, other sustainable development topics. Political inertia prevents this scientific conclusion from being implemented in practice. 
Moving forward with integration as in Figure 1 requires balancing between not reversing progress and forging new pathways whereby separation ends. The three main agreements from 2015 set a 15-year agenda, but are about activities long into the future, so the time to start improving is now.

\section{Further reading}

Four papers which are free to download supplementing this paper are:

- Belesova, K., Kelman, I. and Boyd, R. (2016), "Governance Through Economic Paradigms: Addressing Climate Change by Accounting for Health", Politics and Governance, Vol. 4 No. 4, pp. 87-96, http://www.cogitatiopress.com/politicsandgovernance/article/view/729

- Kelman, I. 2015. "Climate Change and the Sendai Framework for Disaster Risk Reduction". International Journal of Disaster Risk Science, vol. 6, no. 2, pp. 117-127, https://link.springer.com/article/10.1007/s13753-015-0046-5

- Kelman, I., JC Gaillard, J. Lewis, and J. Mercer. 2016. "Learning from the history of disaster vulnerability and resilience research and practice for climate change". Natural Hazards, vol. 82, no. S1, pp. S129-S143, https://link.springer.com/article/10.1007/s11069-016-2294-0

- Kelman, I., JC Gaillard, and J. Mercer. 2015. "Climate Change's Role in Disaster Risk Reduction's Future: Beyond Vulnerability and Resilience". International Journal of Disaster Risk Science, vol. 6, no. 1, pp. 21-27, https://link.springer.com/article/10.1007/s13753-015$\underline{0038-5}$

\section{References}

Fleuret, A. (1986), "Indigenous responses to drought in sub-Saharan Africa”, Disasters, Vol. 10 No. 3, pp. 224-229.

Kelman, I. (2015), "Climate Change and the Sendai Framework for Disaster Risk Reduction", International Journal of Disaster Risk Science, Vol. 6 No. 2, pp. 117-127.

Knutson, T.R., McBride, J.L., Chan, J., Emanuel, K., Holland, G., Landsea, C., Held, I., Kossin, J.P., Srivastava, A.K. and Sugi, M. (2010), "Tropical cyclones and climate change", Nature Geoscience, Vol. 3, pp. 157-163.

Menoni, S. (2001), "Chains of damages and failures in a metropolitan environment: some observations on the Kobe earthquake in 1995", Journal of Hazardous Materials, Vol. 86, pp. 101-119.

UNFCCC (2015), Conference of the Parties, Twenty-first session, Paris, 30 November to 11 December 2015, FCCC/CP/2015/L.9/Rev.1. UNFCCC (United Nations Framework Convention on Climate Change), Bonn.

UNGA (2015), Resolution adopted by the General Assembly on 25 September 2015, A/RES/70/1. UNGA (United Nations General Assembly), New York, NY.

UNISDR (2015), Sendai Framework for Disaster Risk Reduction 2015-2030. UNISDR (United Nations Office for Disaster Risk Reduction), Geneva.

Wisner, B., Blaikie, P., Cannon, T. and Davis, I. (2004), At risk: Natural hazards, people's vulnerability and disasters, 2nd edition. Routledge, London. 